\title{
11
}

\section{A strategic partnership in outsourcing: a public sector case study}

\author{
C. A. Davies, T. Campbell \\ School of Management, \\ Queens University, \\ Belfast, \\ Northern Ireland. \\ Tel 01232273204 \\ Fax 01232248372 \\ e-maila.davies@qub.ac.uk
}

\begin{abstract}
This paper presents a case study of the outsourcing process in the Central Information Systems Division of the Northern Ireland Civil Service. This was one of the earliest examples of a central government computing service being outsourced. This is held to be a successful partnership due to mutual reliance. The effects of outsourcing in general in the public sector are discussed. These are compared with the potential benefits of outsourcing and the situational framework defined by Earl.
\end{abstract}

\section{Keywords}

Information systems, public administration, outsourcing

\section{INTRODUCTION}

In this paper the authors describe the first major government outsourcing project in the United Kingdom. The effects on service levels and staff are investigated. The findings are analysed in the context of Earl's framework for outsourcing. This is seen to be an example of successful outsourcing due to a strong strategic partnership between the two organisations. 


\section{CASE STUDY}

This case study is compiled from a series of fourteen interviews carried out in the autumn of 1993. The interviewees were representative of users, former Northern Ireland Civil Service staff and staff who remained within the public sector.

The Central Information Systems Division (CISD) of the Department of Finance and Personnel (DFP) of the Northern Ireland Civil Service was established in 1984 with the following responsibilities:

- the development in conjunction with departments, of an overall information technology strategy;

- the development and operation of common information technology systems;

- the provision of information technology advice and guidance;

- the recruitment, training and career development of information technology staff;

- the provision of a central procurement service for computers and information technology related equipment and

- the provision and maintenance of a central mainframe bureau service (Northern Ireland Audit Office, 1992).

The mainframe bureau service for all NICS departments comprised the running of some 80 applications on 3 ICL mainframes. The applications included payroll, accounts and statistical analysis work. As part of the same strategy an Information Systems Unit was established in each of the 6 Northern Ireland departments (see figure 1). The responsibilities of the ISUs were:

- the planning of departmental information technology needs;

- the development and operation of information technology applications and

- the provision of technical support in pursuit of departmental aims and objectives. 


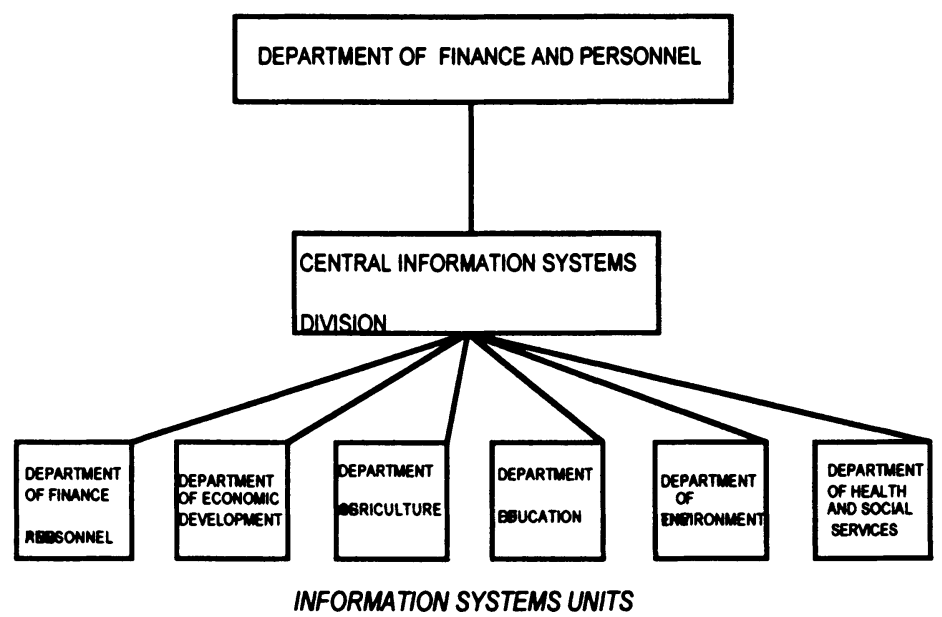

Figure 1 Structure of Central Information Systems Division

The increasing decentralisation of work towards the ISUs combined with a technological shift away from mainframe power to microcomputing systems resulted in a declining workload for CISD. This led to CISD becoming apparently uneconomic with decreasing numbers of applications which in turn meant that the remaining applications were having to bear the increasing overheads. Expenditure on IT in total had increased from $£ 7.5$ million in $1984-85$ to a peak of $£ 32.01$ million in 1989-90. Increasing costs and government policy led senior managers to consider measuring the performance of the bureau service against that of a private sector company in a market testing exercise. Market testing involves ascertaining the value for money of in-house services against tenders from outside organisations (Government purchasing service, 1991). This process took place at CISD before the term market testing was in common currency. The parallel concept of compulsory competitive tendering was launched in local government in 1988. The emphasis in the United Kingdom public sector has been one of increasing efficiency and maximising value for money. Previously, increased efficiency in the public sector was sought through internal investigations of processes for example, under the Rayner efficiency scrutinies. The idea of measuring the performance of public sector services against private sector suppliers was gaining currency. Government policy laid increasing emphasis on efficiency through competition in the market-place. 


\subsection{The outsourcing process}

Beginning in February 1989 a feasibility study was carried out over the subsequent 9 months to ascertain the viability of putting the central computing service out to tender. This aimed to ascertain the level of interest from the Northern Ireland IT industry. It was determined that the tendering process would applicable and in September 1989 the initial invitation to tender was issued and it received 16 responses. From these responses it was reduced to 6 tenders which included the inhouse bid. The tenders were subsequently narrowed down to 3 external organisations and final offers were received. In June 1991 the decision was taken to outsource the bureau service with ICL. In the interim period, ICL's facilities management operation was merged with CFM Limited in which ICL had taken a $75 \%$ share. It was therefore CFM who signed the contract. The changeover took place in September 1991, to run for 10 years with a review after 5 years. The selection criteria for the outsourcing company took into account a number of factors including value-for-money, quality of service, the ability to take the majority of CISD staff and to ensure a smooth changeover.

The contract was to cover the work of 7 government departments and their executive agencies, some 66 applications in total. Some applications were excluded on grounds of their stage in the development process. The outsourcing contract is estimated to be achieving savings of $£ 1.8$ million per annum in a function valued at $£ 6.2$ million (H M Treasury, 1991).

The outsourcing deal was initially going to involve 259 staff, but eventually, after the exclusion of some areas, covered 190 staff. In a period of great uncertainty staff felt that the communication process - a system of memos, briefings and presentations was effective. The trade unions were actively involved in the process. The issue of the Transfer of Undertakings legislation did not arise.

\subsection{Contract monitoring}

The agreement between CFM and NICS consists of a central contract concerned with the overall service and a service level agreement for each of the now 40 individual applications. The contract is managed at three levels - user, departmental and the Business Development Service (BDS) central team. The individual users monitor the service they receive against their service level agreement and verify reports. Departmental representatives check a four-weekly performance report from CFM. The BDS Central Monitoring Group (CMG) is made up of 3 managers whose job it is to monitor the overall contract. They have quarterly meetings with representatives from CFM and departmental representatives to discuss any problems that may have arisen. For those staff who are involved in monitoring the contract a new range of skills is required. In particular the CMG now require improved negotiating skills contract monitoring and accounting skills. Those at departmental level have to pay attention to detail in the examination of the reports. 


\subsection{CISD staff}

The majority of staff who stayed within the NICS have moved to administrative or clerical work outside the IT function. Many of the staff who stayed within the new unit Business Development Service (BDS) were to be engaged in contract monitoring instead of operational activities. BDS resulted from a merger with two other units of the Department and Finance and Personnel, Management Services and the training function - Management Development Centre.

It would appear that those staff who remained within the parent unit underwent the greater amount of change. The environment of the public sector which, prior to the market testing programme had been very stable, had become much more turbulent. This was due to the increased pace of market testing initiatives and the effects of government policy epitomised in New Public Management. IT functions were more frequently included in designations of areas for testing.

\subsection{Staff who transferred}

CFM selected 110 of the 190 former CISD staff by means of formal recruitment procedures. These staff would appear to have adapted well to the move to the private sector. The stated reasons for transferring were that they wished to stay in their functional speciality. To a greater or lesser extent they were carrying out the same tasks, but for a different employer. They felt that if they had stayed within the NICS they would have been transferred to another function. Equally there was a perception of increased status as they were no longer merely part of a support function, rather they were now part of a company whose business was IT.

Staff who transferred were attracted by the increased emphasis on an individual's performance and responsibility. Not only were they responsible for the work they had originally carried out at CISD but they were given additional duties which have led to an increased variety of work and also increased responsibility.

From the early stages staff have been part of continuous training programmes designed to help them improve their work and to give them a more customeroriented approach.

\subsection{Service delivery}

The users interviewed felt that the service levels offered by CISD had been of a high standard. However, the overall quality of service delivered by the outsourcing company is perceived to be even better. This may be due to the customer-oriented approach which has led to reduced response times to queries. The external company is also perceived to be more 'business like' in its approach. Equally it is worth noting that prior to the outsourcing contract many users were unaware of the level of service they were receiving. The documentation of service level agreements has 
raised user awareness. This has led users to speculate if the savings could have been achieved in house.

This contract is held to be successful by all concerned, users, former CISD staff, both those now in BDS and in CFM. Suggested reasons for the success include a process of good contract management, which is essential for an outsourcing arrangement's viability. Some interviewees commented on the information management problem contract monitoring was itself generating.

There are good working relations between CFM and BDS. Initially CFM actually used part of the CISD/BDS premises as well as employing many of CISD staff. These experienced staff trained in CISD procedures are another contributing factor to the smooth running of the operation. There is a strong bond between the two organisations. Finally the in-depth preparation of the market testing process gave senior managers a deep insight into the workings of the service.

The major negative feature lies in the effect on staff morale of those who remained within the Northern Ireland Civil Service. Having come through one period of radical change, they would appear to be sceptical of future developments.

\section{DISCUSSION}

In 10 years the information technology function of the NICS has moved from a centralised service to a more federal structure. The central operational level has subsequently been contracted out to an external supplier. The central strategic function has been retained. In this case the vendor organisation is supplying a commodity service. The relationship is operating on both a contractual and cooperative level (Willcocks and Kern, 1997). While outsourcing might be considered a decentralisation measure, it represents a centralisation of operational activities, but monitoring is carried out at departmental level. Strategic planning continues to be the remit of the central group in the existing federal structure (see figure 2). There is a true partnership as each organisation is reliant on the other. NICS relies on CFM (NI) for technical services, this contract was a flagship for the establishment of CFM (NI), so it is committed to client satisfaction beyond their high standard of customer care. 


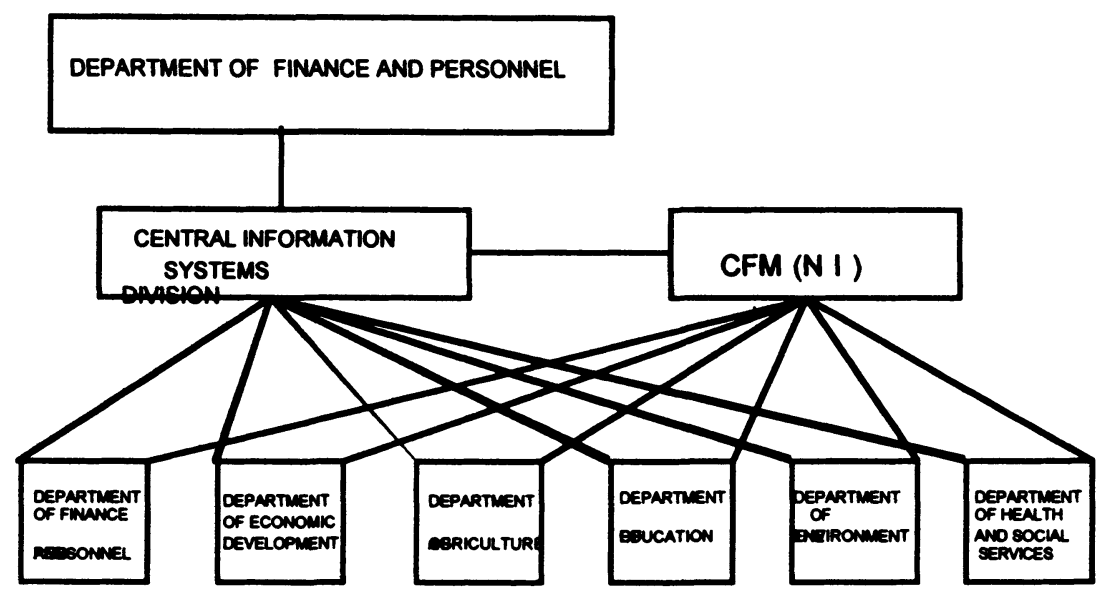

INFORMATION SYSTEMS UNITS AND CUSTOMERS

Figure 2 Structure of Central Information Systems Division after outsourcing.

There has been a major depletion in the number of technically expert staff, with the transfer of almost $60 \%$ of staff to the private sector. This raises the issue of succession planning for senior staff in the remaining core. The general issue of the impact of the market testing initiatives on staff morale in the public sector cannot be overlooked.

The number of mainframe applications contracted out to the outsourcing company is steadily decreasing, from an initial 66 to 47 . The next logical step from the government's point of view would be for the work of the ISUs to be market tested. This may prove more difficult to achieve.

\subsection{Benefits of outsourcing}

The benefits of outsourcing can now be investigated in the light of this case study. Earl gives the following as the putative benefits of outsourcing:

- cost reduction,

- the opportunity to focus on core business,

- increased quality,

- additional flexibility and

- increased accountability. 
In the case of CISD, the cost reductions have been estimated at $£ 1.8$ million per annum. More importantly, uncertainty about costs has also now been reduced as costs are agreed in the outsourcing contract. This viewpoint only includes production costs, transaction costs are excluded. Williamson defines transaction costs as the costs of monitoring controlling and managing transactions. As Hirschheim (1993) indicates, managers must consider the total costs, both production and transaction costs, when considering the outsourcing option. The work of the BDS central monitoring team was costed in to the contract. In the drive for efficiency, policy-makers must consider the transaction costs.

The opportunity to concentrate on the core business of the organisation exists for all those not involved in the monitoring process. Some users have found the detail of contract monitoring more time consuming than first anticipated.

Increased quality of service is perceived to have resulted from the fast response times to queries from the outsourcing company as part of its customer-oriented culture. On the one hand, it can be posited that with such a reduction of in-house technical staff, the potential for impartial advice may be limited and the ability to determine service quality may be diminished. On the other hand outsourcing gives access to IT specialists. For the public sector, staff recruitment has traditionally been problematic. CISD had been unable to realise its recruitment targets due to a combination of market forces, where demand for experienced information technology staff had continually outstripped supply, and due to the lengthy recruitment process (Northern Ireland Audit Office 1992).

The opportunity for increased flexibility would appear to be very limited, as the service is bound contractually to one company. There is little prospect of the service returning in its present form to an in-house operation. If another supplier had to be found, the detailed procurement procedures which have already been negotiated would have to be redone. The balance of power weighs heavily in the vendor's favour due to the dependency relationship. There is a trade-off between flexibility and cost containment.

It is evident that clearer lines of accountability do exist which were cited by both users and CFM staff as being beneficial. However clear accountability stems from the contract specification, especially the accuracy and comprehensiveness of service level agreements. It was pointed out that internal service level agreements might have achieved the same result.

There are some benefits which can be realised for the public sector, particularly in the areas of 'fixing' costs and having access to a cadre of specialised staff. Some of the other benefits, notably flexibility, would appear to be unlikely to be realised.

\section{FRAMEWORK FOR SOURCING}

Earl's framework for making the sourcing decision bears scrutiny in the context of this case study (see figure 3). Above all, CISD gave an example of low risk mature technology, CFM are supplying a commodity to the client organisation. The threat 
of loss of security of information should be one which is of particular significance to the public sector. Information stewardship lies at the very heart of the role of the public servant. Ascher writing in 1987 commented on the indivisibility of services when examining IT operations, indicating the difficulty of separating IT systems from the work of the organisation. In terms of actual data security, CFM staff are bound by Official Secrets legislation and staff commented that there was increased emphasis on data security as any breaches would have serious contractual implications.

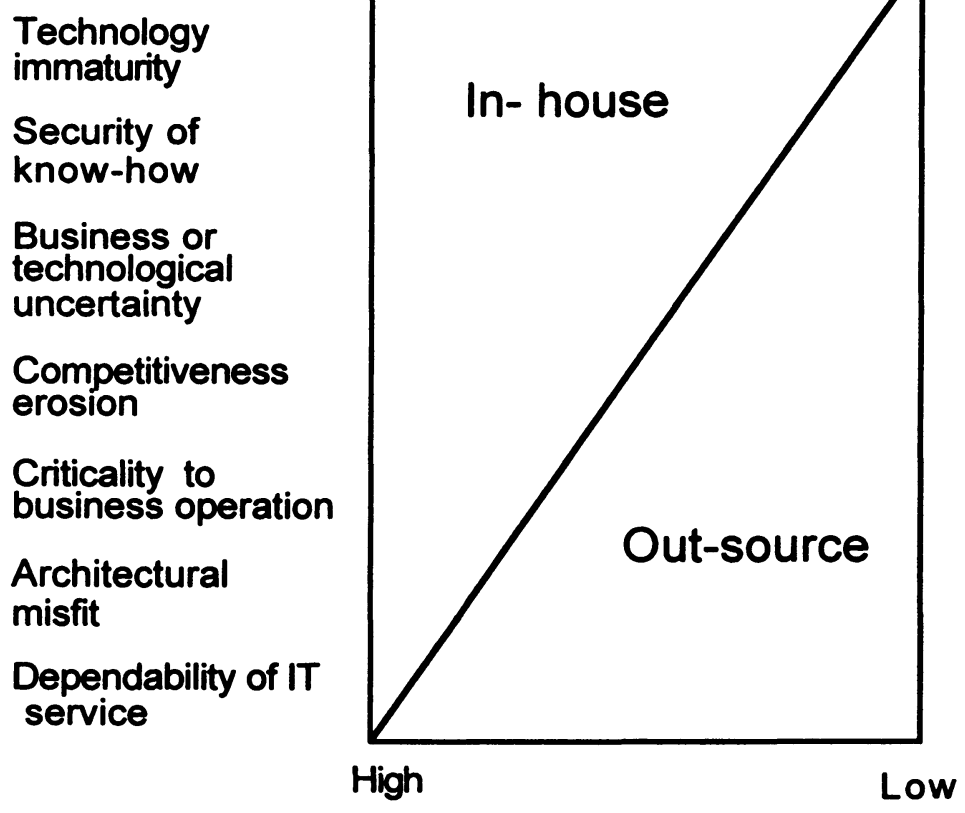

Figure 3 Outsourcing: situational factors (Earl 1991)

The pace of government reforms in the United Kingdom in the past 10 years has made the public sector as prone to uncertainty as many businesses. Major structural changes have occurred in government departments with the separation of the policy making function from the executive agencies under the Next Steps programme. Technological uncertainty for the moment may be low, but the use of optical methods for information storage and retrieval techniques are potentially of relevance to the public sector. The interpretation of erosion of competitiveness concerns the 
criticality of the information service to the organisation. This is an important consideration for the public sector. Taylor (1992) has put forward the concept of the 'information polity' which recognises the role of information in energising organisations. Outsourcing could have two effects on the information polity. By concentrating attention on information-related issues, outsourcing enhances this state. On the other hand, as a logical extension to Ascher's viewpoint, it may be difficult to separate the information content from the technological means of delivery.

In this case architectural fit was not a problem as the outsourcing company is linked to a proprietary supplier. Information services performance assumes importance if a department consistently underperforms. Earl cites the typical reaction that if 'IS is broke then let's put it out to tender'. A generally and perhaps undeserved perception of poor practice in public sector computing would appear to prevail. For example, in the United Kingdom National Health Service, a perception exists that valuable money is wasted on computers which could be better devoted to direct patient care. This may be explained by public accountability where bodies such as the Audit Office and Public Accounts Committee report on IT failures in the public sector. Similar cases in the private sector escape attention.

Four of the six criteria suggested by Earl have limited applicability to the public sector. As ever, it is in the technological criteria that the transition is smoothest. Assessed against this framework it would seem that outsourcing needs to be considered judiciously. Overall, the underlying rationale behind market testing in IT services in the public sector has been a political one. The absence of the mythical level playing field was commented upon by more than one interviewee. The outsourcing arrangement in this case study has been successful due to an effective partnership between the two organisations. It constitutes a strategic alliance due to the equality of the partners. Other public sector outsourcing arrangements may not enjoy the same level of success.

\section{CONCLUSIONS}

This earliest example of contracting out of an IT service in the public sector merits examination. The outsourcing contract would appear to be working well due to good relations between the two organisations. The meticulous preparation of those concerned in the in-house bid was of significant benefit in compiling and managing the contract. On comparing the case study against Earl's framework for evaluation, two thirds of the criteria are open to question in the public sector. The wider issues of information stewardship and informatization in public administration may be undermined by such policies as outsourcing. 


\section{REFERENCES}

Ascher, K. (1987) The politics of privatisation. Macmillan, London.

HM Treasury (1991) Competing for quality. London, HMSO.

Earl M J (1991) Outsourcing information services Public money and management Autumn 17-21.

Government purchasing service (1991) A guide to market testing in Government. GPS, Belfast.

Lacity, M. C. and Hirschheim, R. (1993) Information systems outsourcing. Wiley, Chichester.

Northern Ireland Audit Office (1992) The management of information technology in government departments in Northern Ireland. London, HMSO .

Taylor J. A. (1992) Information networking in public administration. International Review of Administrative Sciences, 58, 375-389.

Willcocks, L. and Kern , T. (1997) IT outsourcing as strategic partnering: the case of the UK Inland Revenue. Proceedings of the fifth European Conference on Information Systems, Cork, 3, 1470-89.

\section{BIOGRAPHY}

Anne Davies is a senior lecturer in information management at the School of Management, Queen's University, Belfast. She teaches and researches in the area of public sector information systems particularly in health care. She has published work in the areas of information systems failures and information strategies.

Trevor Campbell is an Information Management graduate who undertook a postgraduate diploma in research methods at Queen' University. He is currently employed as a statistician in the Northern Ireland Civil Service. 